\title{
Successful treatment of interstitial pregnancy with high level of $\beta$-human chorionic gonadotropin using methotrexate injection
}

\author{
Shen J*, Hosoi A, Onoue M, Yano Y, Hatta K, Takayama T, Yoshimi K, Ozaki K, Saeki N, Funato T and Hashimoto N \\ Department of Obstetrics and Gynecology, Nippon life hospital, 2-1-54, Enokojima, Nisi-ku, Osaka, Japan
}

\begin{abstract}
Interstitial pregnancy is a rare disease and an optimal treatment has not been established due to its rarity. Here, we experienced a case of successful treatment of interstitial pregnancy with a high level of $\beta$-human chorionic gonadotropin ( $\beta$-hCG) using systemic methotrexate (MTX) injection. This case was of a 40-year-old woman, gravida 0 and para 0 . She became pregnant via in vitro fertilization and embryo transfer. In the gestational week of $6^{3+}$, although the level of serum $\beta$-hCG was higher than $10000 \mathrm{mIU} / \mathrm{ml}$, no gestational sac was seen in uterine cavity. The MRI examination revealed that the patient had an interstitial pregnancy. Considering the patient`s strong desire for future fertility and clinical findings, she was given a single-dose intramuscular MTX injection for twice. The $\beta$-hCG level decreased and reached negative values smoothly.
\end{abstract}

\section{Introduction}

Interstitial pregnancy is a rare kind of ectopic pregnancy. It is defined as a pregnancy in which the product of conception is implanted in the intramural portion of the fallopian tube [1]. Ectopic pregnancies account for approximately $2 \%$ of all recognized pregnancies, while interstitial pregnancies account for less than $2-4 \%$ of all ectopic pregnancies [2]. Although the overall mortality rate in ectopic pregnancies has decreased, the maternal mortality rate in interstitial pregnancies remains in the range $2-2.5 \%$. Here, we report a case of successful treatment of interstitial pregnancy with a high level of $\beta$-human chorionic gonadotropin ( $\beta$-hCG) using systemic methotrexate (MTX) injection.

\section{Case presentation}

The patient was a 40 -year-old woman, gravida 0 and para 0 , with no unusual personal or family history. She experienced menarche at the age of 14 , and her menstrual cycle was regular with 28 -day cycles. She became pregnant via in vitro fertilization and embryo transfer, which increases the risk of interstitial pregnancy.

Although transvaginal ultrasonography (TV-US) performed in the gestational week of $6^{3+}$ revealed an empty uterine cavity, the level of $\beta$-hCG serum in her blood was $10211 \mathrm{mIU} / \mathrm{ml}$. We did not observe any specific indication of interstitial pregnancy, such as presence of a separate gestational sac within $1 \mathrm{~cm}$ of the lateral edge of the uterine cavity. Both ovaries appeared normal and no free fluid was noted in the Douglas cavum during the TV-US. Hence, we decided upon a magnetic resonance imaging (MRI) examination. The MRI examination revealed that the patient had a bicornuate uterus (Figure 1a). Although a $12 \mathrm{~mm}$ fetal sac was observed in the left uterine corner, fetal heartbeat was not found (Figure 1b,c,d). A small amount of liquid was present in the Douglas cavum, albeit without any sign of bleeding. Both ovaries were normal. (a)

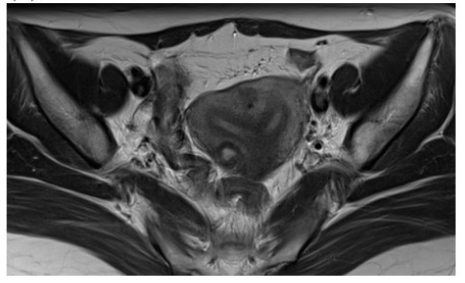

(c)

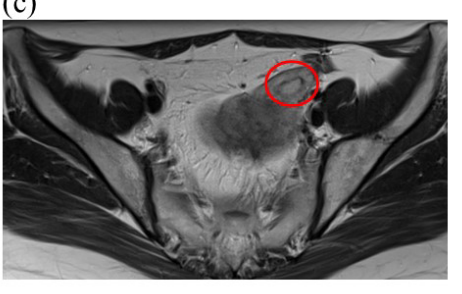

(b)

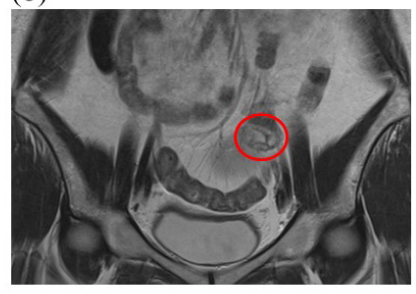

(d)

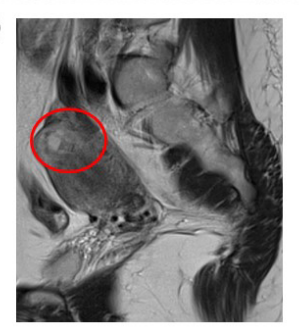

Figure 1. The MRI examination revealed that the patient had a bicornuate uterus (Figure 1a). Although a $12 \mathrm{~mm}$ fetal sac was observed in the left uterine corner, fetal heartbeat was not found (Figure 1b,c,d). A small amount of liquid was present in the Douglas cavum, albeit without any sign of bleeding

Based on the MRI examination and clinical laboratory data, normal pregnancy was excluded, and dilation and curettage were performed. The level of $\beta$-hCG level did not decrease on the following day (Figure 2 ), and interstitial pregnancy was confirmed

Considering the patient's strong desire for future fertility, hemodynamic stability, size of the mass (diameter $<4 \mathrm{~cm}$ ), and

*Correspondence to: Jiao Shen, Obstetrics and Gynaecology department, Nippon life hospital, 2-1-54, Nisi-ku, Osaka, Japan, Tel: 06-6443-3446; E-mail: shenyang51@hotmail.com

Key words: interstitial, pregnancy, methotrexate, treatment

Received: May 11, 2018; Accepted: May 18, 2018; Published: May 22, 2018 
Level of serum hCG, $\mathrm{mIU} / \mathrm{ml}$

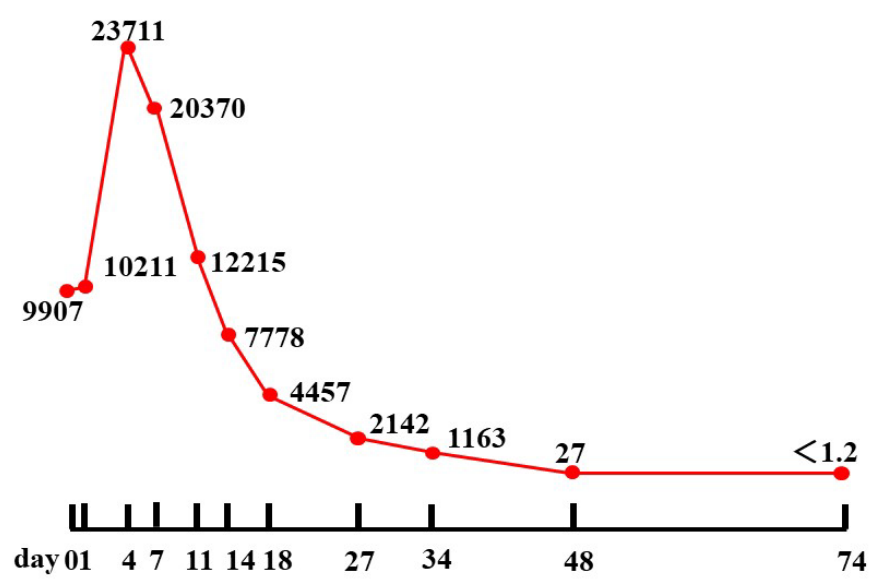

Figure 2. The level of $\beta$-hCG level did not decrease on the following day of dilation and curettage (day 1), Intramuscular MTX injections were performed on day 1 and 7. Although the blood $\beta$-hCG level increased on the $4^{\text {th }}$ day after MTX injection in comparison to that on the day before MTX injection $(23771 \mathrm{mIU} / \mathrm{ml}$ versus $10211 \mathrm{mIU} / \mathrm{ml})$, a decrease of more than $15 \%$ was observed in the $\beta$-hCG levels between days 4 and 7 after the injection ( $23771 \mathrm{mIU} / \mathrm{ml}$ and $20370 \mathrm{mIU} / \mathrm{ml}$ on days 4 and 7 , respectively). And then, the $\beta$-hCG level decreased smoothly and reached negative values on the $74^{\text {th }}$ day after MTX injection.

absence of hematologic, renal, and hepatic impairment, MTX therapy was recommended as the first treatment option. The patient was given a single-dose intramuscular MTX injection $\left(50 \mathrm{mg} / \mathrm{m}^{2}\right)$ on day 1 . She was hospitalized for fourteen days and the level of $\beta$-HCG serum in her blood was monitored after MTX injection. Although the blood $\beta$-hCG level increased on the $4^{\text {th }}$ day after MTX injection in comparison to that on the day before MTX injection $(23771 \mathrm{mIU} / \mathrm{ml}$ versus $10211 \mathrm{mIU} / \mathrm{ml})$, a decrease of more than $15 \%$ was observed in the $\beta$-hCG levels between days 4 and 7 after the injection $(23771 \mathrm{mIU} / \mathrm{ml}$ and $20370 \mathrm{mIU} / \mathrm{ml}$ on days 4 and 7, respectively, a decrease of $3401 \mathrm{mIU} / \mathrm{ml})$. The patient did not suffer any side effects besides nausea after treatment. Kim et al. have suggested that most cases of single-dose MTX treatment fail [3]. In our case, the $\beta$-hCG level increased to a high level on day $7(20370 \mathrm{mIU} / \mathrm{ml})$. Hence, we administered an additional injection of MTX with the same dose on day 7 . The $\beta$-hCG level decreased smoothly and reached negative values on the $74^{\text {th }}$ day after MTX injection (Figure 2).

\section{Discussion}

Interstitial pregnancy is a rare but dangerous form of ectopic pregnancy whose incidence has increased due to the increased use of assisted reproductive technology procedures. Although various approaches for treating this disorder have been reported previously, an optimal treatment regimen has not been established due to its rarity [1].

Traditional treatment of interstitial pregnancy involves surgery including hysterectomy and cornual resection via laparotomic or laparoscopic approaches. This may adversely affect subsequent pregnancies with the possibility of uterine rupture during subsequent pregnancies. Several medical treatments, including systemic or local MTX treatment, have been attempted, yielding largely satisfactory results and success rates between $66-100 \%$ [4-6]. Early gestation age, diameter $<4 \mathrm{~cm}$, and $\beta$-hCG serum levels $<10000 \mathrm{mIU} / \mathrm{ml}$ are essential for selecting medical treatment. However, the $\beta$-hCG level in this case was greater than $10000 \mathrm{mIU} / \mathrm{ml}$ and increased to nearly twice on day 4 , nevertheless, the patient was successfully treated with MTX. Thus, our experience in this case indicates that $\beta$-HCG level is not an absolute predictive factor of the success of MTX treatment. The most suitable treatment option should be selected based on individual patient factors.

\section{References}

1. Takeda A, Koyama K, Imoto S, Mori M, Sakai K, et al. (2009) successful management of interstitial pregnancy with fetal cardiac activity by laparoscopic-asisted corneal resection with preoperative transcatheter uterine artery embolization. Arch Gynecol Obstet 280: 305-308. [Crossref]

2. Shen L, Fu J, Huang W, Zhu H, Wang Q, et al. (2014) Interventions for non-tubal ectopic pregnancy. Cochrane Database Syst Rev 7. Art No. CD011174.

3. Kim MJ, Cha JH, Bae HS, Kim MK, Kim ML, et al. (2017) Therapeutic outcomes of methotrexate injection in unruptured interstitial pregnancy. Obstel Gyneco Sci. 60: 571-578. [Crossref]

4. Panelli D, Phillips CH, Brady PC (2015) Incidence, diagnosis and management of tubal and non-tubal ectopic pregnancies, A review. Fertil Res pract. 1: 15. [Crossref]

5. Parker VL, Srinivas M (2016) non-tubal ectopic pregnancy. Arch Gynecol Obstet. 294:19-27.

6. Sagiv R, Debby A, Keidar R, Kerner R, Golan A (2013) Interstinal pregnancy management and subsequent pregnancy outcome. Acta Obstet Gynecol Scand 92:13271330. [Crossref]

Copyright: (C2018 Shen J. This is an open-access article distributed under the terms of the Creative Commons Attribution License, which permits unrestricted use, distribution, and reproduction in any medium, provided the original author and source are credited. 